late reaction rates in this same way for reactions in solution, the calculated rates are too large, and that a probability factor, $P$, must be introduced, which represents the chance of reaction at a collision involving activated molecules. The values found for $P$ in a few reactions range from $4 \times 10^{-11}$ to $4.92 \times 10^{-5}$. The explanation which they offer for these very small values of $P$ is that simple binary collisions seldom occur, and that a third molecule will often remove a portion of the energy and thus cause deactivation.

It seems to me that the effect of the third molecule should be activational in some cases, perhaps as often as it is deactivational, and that in any case the explanation of the small values found for $P$ does not lie entirely in the frequency of ternary collisions. There are two other reasons, which were not sug gested by Norrish and Smith, which would lead to small values of $P$, and to a great range of variation in these values. The first of these is the solvation of the reactant molecules, which should be expected to shield them from each other, reducing the chance of reaction upon collision by a factor which does not appear to be predictable. This effect should have a temperature coefficient, and there is thus the possibility that in some cases the value of $E$ calculated from the overall temperature coefficient of the reaction will be too large; the calculated value of $P$ would then be too large also, since the exponential term would be too small. An effect such as this is thus capable of accounting for large variations in the value of $P$.

The other reason why $P$ should be small in all the reactions considered is to be found in the complexity of the reactant molecules. One of the reactions, for example, is between nitrobenzyl chloride and trimethyl amine. It is surely to be expected that a very special orientation at collision is a necessary condition for reaction in such a case; in the bimolecular gas reactions, which involve quite simple molecules, such as nitrous oxide, the orientation is of course of much less importance, but for these complex organic molecules a contribution to $P$ of the order of $10^{-6}$ from this factor would not seem to be unreasonable.

There thus seems to be ample reason for expecting $P$ to be small for reactions of the type studied by Norrish and Smith, and for it to vary markedly from one reaction to another, and even with change of solvent for the same reaction. There appears, however, to be slight chance of deriving even rough theoretical values. Indeed, the simple kinetic theory expression for the number of collisions is of doubtful validity in condensed systems.

Gates Chemical Laboratory,

Louis S. Kasser.

California Institute of Technology, Feb. 22.

Glot Bey and the Gairo School of Medicine.

My attention has been directed to two paragraphs in the News and Views columns of Nature of Jan. 14 concerning the centenary celebration of the School of Medicine, Cairo, and the International Congress of Tropical Medicine and Hygiene. It is stated in those paragraphs that "The story goes that one afternoon the Viceroy Mohammed Ali was driving through the streets of Cairo on the way to Shubra Palace when he ordered his coachman to stop, and summoning a well-dressed Frenchman who was walking along the streets, informed the stranger that he wanted him to create a Medical School in Cairo. . . . Clot Bey, in spite of his ignorance of medicine, was an able man, who accomplished the task thus en- trusted to him with conspicuous success, which was recognised later by the conferring of the M.D. degree on him by the University of Paris."

The facts are that Dr. Clot, who was already a qualified French medical man, was called in 1825 to come to Egypt to organise the Medical Service of the Egyptian Army. He was followed by 154 European medical officers and apothecaries. It was only in 1827, that is, two years after his arrival in Egypt, that he started the Medical School. There is at the School of Medicine most of the literature of the time bearing out the authenticity of these facts. Dr. F. M. Sandwith, in a paper on the history of Kasr-elAini Hospital, A.D. 1466-1901, that appeared in the records of the Egyptian Government School of Medicine in 1901, mentions the details of the foundation of the School and gives many references on the subject.

In view of these facts, I can scarcely imagine that there could be any authentic source for the romantic account of the foundation of the Cairo Medical School referred to above.

Faculty of Medicine, Cairo.

I AM sorry that Prof. Khalil has demolished the romantic tradition of Clot Bey, which for many years I had firmly believed to be the true story of the founding of the Cairo School of Medicine. In extenuation of my lapse in giving a new and wider circulation to this myth, I should explain that the brief statement referred to summarised my recollection of an elaborate and very circumstantial story given me years ago, when the late Dr. Sandwith was writing his history, by men who seemed to speak with intimate knowledge and authority. I am willing to admit that the British members of the staff of the Cairo School of Medicine in those days included several raconteurs of quite exceptional inventiveness, but $I$ never had any reason to assume that this narrative was not true. The whole point of the story, as I heard it, was to emphasise the argument that the high efficiency of a medical school such as Clot Bey had created in Cairo was due to his administrative ability and judgment in selecting the right men for his staff.

The Writer of THE Notes.

\section{The Correction of Astigmatism.}

Even the more scientific members of the optical profession scarcely seem to be aware of their debt to mathematics for the discovery of the modern method of adjusting spectacle-lenses to suit astigmatic eyes. It is generally known that the first person to use cylindrical lenses for this purpose was Sir George Airy. During his tenure of the Lucasian professorship at Cambridge (1826-28), he had a pair of cylindrical lenses ground which corrected his own eye-sight. But we owe the complete general theory to a later Lucasian professor, Sir George Stokes (1849-1903), who was the first to prove mathematically that any eye (whether long-sighted or short-sighted) can be corrected for astigmatism (as well as these other defects) by using a lens which has one face spherical and the other cylindrical. ${ }^{1}$

To explain the importance (on the practical side) of Stokes's theorem, a few simple calculations may be added : an adequate outfit for an oculist may be taken to consist of 100 lenses $(60$ spherical and 40 cylindrical, the other faces being plane, in each case), combined with instruments to measure the

1 For more details, any of the more advanced books, for example, Herman's "Geometrical Optics," ch. x. art. 174, may be consulted.

No. 3054, VoL. 121] 